\title{
Fentanyl inhibits proliferation and invasion via enhancing miR-302b expression in esophageal squamous cell carcinoma
}

\author{
NING WANG, ZHENNI ZHANG and JIANRUI LV \\ Department of Anesthesiology, Second Affiliated Hospital, Medical School, \\ Xi'an Jiaotong University, Xi'an, Shaanxi 710002, P.R. China \\ Received August 4, 2016; Accepted January 17, 2018
}

DOI: $10.3892 / \mathrm{ol} .2018 .8616$

\begin{abstract}
Fentanyl is one of the most commonly used intravenous anesthetic agents during cancer resection surgery, but the effect of fentanyl on esophageal squamous cell carcinoma (ESCC) remains unclear. The aim of the present study was to investigate the involvement of microRNA 302b (miR-302b) in the anti-proliferation and anti-invasion effects of fentanyl in ESCC. In the present study, the effects of fentanyl on cell proliferation, apoptosis and invasion were detected using MTT assays, flow cytometry and Transwell assays in ESCC Eca109 and TE1 cell lines. Subsequently, expression of miR-302b was determined using reverse transcription-quantitative polymerase chain reaction (RT-qPCR). RT-qPCR and western blot analysis were performed in order to evaluate the expression of ErbB4, a target of miR-302b. Furthermore, anti-miR were used to inhibit miR-302b in fentanyl-treated ESCC cells in order to evaluate the role of miR-302b in the effect of fentanyl on malignant behaviors. Fentanyl inhibited the proliferation of Eca109 and TE1 cells in a dose- and time-dependent manner. Following exposure to fentanyl for 48 h, Eca109 and TE1 cells exhibited increased apoptosis and decreased invasion. Furthermore, fentanyl upregulated miR-302b expression, but downregulated ErbB4 expression. Finally, loss of miR-302b using the anti-miR technique reversed the effect of fentanyl on cell proliferation, apoptosis and invasion in the two ESCC cell lines. Taken together, the results of the present study indicated that fentanyl inhibits the proliferation and invasion of ESCC cells through upregulation of miR-302b.
\end{abstract}

Correspondence to: Professor Jianrui Lv, Department of Anesthesiology, Second Affiliated Hospital, Medical School, Xi'an Jiaotong University, 157 Xiwu Road, Xi'an, Shaanxi 710002, P.R. China

E-mail: dodosasa@126.com

Key words: fentanyl, microRNA 302b, esophageal squamous cell carcinoma, proliferation, invasion

\section{Introduction}

Esophageal carcinoma (EC) remains one of the leading causes of cancer-associated mortality (1), with a 5-year survival rate of $<20 \%$ (2). EC usually occurs as either adenocarcinoma or squamous cell carcinoma (ESCC), the latter of which is more dominant in East Asia and accounts for $95 \%$ of all Chinese EC cases (3). Given this, there is an urgent requirement for research to prevent and treat this disease.

Fentanyl, a strongly anesthetic analgesic drug, is an agonist for the $\mu$-opioid receptor and is widely used in surgery, including tumor radical resection (4). Furthermore, it is considered to be an effective analgesic for breakthrough cancer pain in patients with terminal cancer (5). Recently, an increasing number of studies reported that fentanyl is able to inhibit cancer progression, including proliferation, cell cycle, apoptosis, invasion and chemotherapy sensitivity (6-10). In brief, fentanyl may serve a potential therapeutic role in cancer treatment. However, the effect of fentanyl on ESCC and the mechanism underpinning this remain unknown.

MicroRNAs (miRNAs) represent a class of small non-coding RNAs that regulate gene expression at the post-transcriptional level. One study demonstrated that miRNAs were aberrantly regulated in different oncogenic pathways and/or various types of cancer, indicating that certain miRNAs may function as oncogenes or tumor suppressor genes (11). Previous studies revealed the expression profiles of different miRNAs and identified certain specific miRNAs with biological functions and significance in ESCC (12-14). miR-302b, which was downregulated in ESCC, inhibited cell proliferation, induced apoptosis and reversed invasion in ESCC (13). In addition, it was believed that miR-302b inhibited the malignant behaviors of ESCC by directly targeting ErbB4, a molecular therapeutic target for ESCC (13).

Since fentanyl is able to change miRNA expression profiles in human cancer cells (8), we hypothesized that fentanyl may inhibit the proliferation and invasion of ESCC cells through the miR-302b/ErbB4 pathway. Therefore, in the present study, the effects of fentanyl on the proliferation, apoptosis and invasion of ESCC Eca109 and TE1 cells were investigated. Furthermore, the regulatory effect of fentanyl on the expression of miR-302b and its target, ErbB4, was also examined in order to elucidate the exact mechanism of the antitumor effect of fentanyl in ESCC. 


\section{Materials and methods}

Cell culture and reagents. The ESCC Eca109 and TE1 cell lines were obtained from the Shanghai Institute for Biological Sciences (http://www.cellbank.org.cn/), Chinese Academy of Sciences (Beijing, China). Cells were cultured in RPMI-1640 medium (Sigma-Aldrich; Merck KGaA, Darmstadt, Germany), supplemented with $10 \%$ fetal bovine serum and $100 \mathrm{U} / \mathrm{ml}$ penicillin and streptomycin, at $37^{\circ} \mathrm{C}$ in a humidified atmosphere with $5 \% \mathrm{CO}_{2}$. Fentanyl was purchased from Sigma-Aldrich; Merck KGaA, was dissolved in dimethyl sulfoxide (DMSO) and was added into the culture medium at various concentrations $(0,0.5,5,50$ and $500 \mathrm{ng} / \mathrm{ml})$ for in vitro assays.

Cell proliferation assay. Cells were seeded at a density of $5 \times 10^{3}$ cells/well in 96-well plates at a final volume of $180 \mu \mathrm{l}$ in incubation, at $37^{\circ} \mathrm{C}$ in a $5 \% \mathrm{CO}_{2}$ atmosphere. Following various incubation times $(24,48$ and $72 \mathrm{~h}), 20 \mu \mathrm{l}$ of $5 \mathrm{mg} / \mathrm{ml}$ solution of MTT (Sigma-Aldrich; Merck KGaA) in 1xphosphate-buffered saline (PBS) was added to each well. The plates were subsequently incubated for $4 \mathrm{~h}$ at $37^{\circ} \mathrm{C}$, prior to the reaction being solubilized in $100 \%$ DMSO $(20 \mu \mathrm{l} /$ well $)$ and agitated at $37^{\circ} \mathrm{C}$ for $15 \mathrm{~min}$. The absorbance of each well was measured on a multi-detection microplate reader (BMG Labtech $\mathrm{GmbH}$, Ortenburg, Germany) at a wavelength of $570 \mathrm{~nm}$.

Apoptosis analysis. The cells were washed twice with cold $10 \mathrm{mM} 1 \mathrm{xPBS}$ and were resuspended in 1xbinding buffer (BD Biosciences, San Jose, CA, USA). Cells were then washed twice with PBS and $400 \mu 11 \mathrm{x}$ binding buffer was added followed by $5 \mu 1$ Annexin V-fluorescein isothiocyanate (FITC) conjugate from the FITC Annexin V Apoptosis Detection kit (cat. no. 556547; BD Biosciences). The cells were then incubated in the dark for $15 \mathrm{~min}$ at $2-8^{\circ} \mathrm{C}$, then $5 \mu \mathrm{l}$ PI was added and incubation was continued for $5 \mathrm{~min}$. The samples were analyzed using a flow cytometer (FACSCalibur; BD Biosciences) and analyzed by the Cell Quest software (version 3.3; BD Biosciences).

Cell invasion assay. For the invasion assay, the membrane invasion culture system Transwell membranes with a diameter of $6.5 \mathrm{~mm}$ diameter and a pore size of $8 \mu \mathrm{m}$; Costar (Corning Incorporated, Corning, NY, USA) was used according to the manufacturer's protocol. Briefly, harvested cells $\left(1 \times 10^{5}\right)$, resuspended in $100 \mu 1$ of serum-free RPMI-1640 medium, were added into the upper chamber. A total of 1,000 $\mu \mathrm{l}$ conditioned RPMI-1640 medium with 20\% (v/v) fetal bovine serum was used as a chemoattractant and was placed into the lower chamber. After $48 \mathrm{~h}$, the un-invaded cells on the upper surface of the membrane were removed with a cotton swab. The transformed cells that had invaded through the Matrigel matrix and stuck to the lower surface of the membrane were fixed with $4 \%$ paraformaldehyde for $1 \mathrm{~h}$ at room temperature and stained with $1 \%$ crystal purple for $15 \mathrm{~min}$ at room temperature. The invasive cells were then counted (in 5 high-power fields/chamber) using an inverted microscope (Olympus Corporation, Tokyo, Japan; magnification, x200). Each experiment was repeated in triplicate.
$R N A$ extraction and reverse transcription-quantitative $P C R$ $(R T-q P C R)$. Total RNA was extracted from Eca109 and TE1 cells using TRIzol reagent (Invitrogen; Thermo Fisher Scientific, Inc., Waltham, MA, USA), according to the manufacturer's protocol. RT-qPCR was performed using a Bio-Rad iQ5 Real-Time PCR Detection system to confirm the mRNA expression levels. A reverse transcription kit and SYBR-Green both from Takara Biotechnology Co., Ltd. (Dalian, China) were used. In brief, reverse transcription (RT) was performed in a $20 \mu \mathrm{l}$ volume with $1 \mu \mathrm{g}$ total RNA, by incubation at $16^{\circ} \mathrm{C}$ for $30 \mathrm{~min}, 42^{\circ} \mathrm{C}$ for $42 \mathrm{~min}$ and $85^{\circ} \mathrm{C}$ for $5 \mathrm{~min}$. A total of $1 \mu \mathrm{l}$ of the RT product was used in each PCR. The PCR cycling began with template denaturing at $95^{\circ} \mathrm{C}$ for $5 \mathrm{~min}$, followed by 40 cycles of $95^{\circ} \mathrm{C}$ for $10 \mathrm{sec}, 60^{\circ} \mathrm{C}$ for $20 \mathrm{sec}, 72^{\circ} \mathrm{C}$ for $20 \mathrm{sec}$ and $78^{\circ} \mathrm{C}$ for $20 \mathrm{sec}$. Final PCR products were resolved by agarose gel electrophoresis and a single band of expected size indicated the specificity of the reaction. Relative quantification was performed using the $2^{-\Delta \Delta \mathrm{Cq}}$ method normalized to GAPDH (15). Each PCR amplification was performed in triplicate to verify the results. The primers were as previously described (14).

Western blot analysis. Total proteins were extracted from cells using lysis buffer containing phenylmethyl sulfonylfluoride (both from Beyotime Institute of Biotechnology, Haimen, China) at $25^{\circ} \mathrm{C}$. The protein concentration was determined using BCA Protein Assay kit (Beyotime Institute of Biotechnology). For western blot analyses, $20 \mu \mathrm{g}$ total protein was electrophoresed on a $10 \%$ SDS gel, transferred onto polyvinylidene difluoride membranes, blocked with 5\% (w/v) non-fat dry milk in Tris-buffered saline with $0.1 \%$ Tween-20 for $1 \mathrm{~h}$ at room temperature, and incubated with anti-ErbB4 (cat no. sc-283; 1:500; Santa Cruz Biotechnology, Inc., Dallas, TX, USA) and anti- $\beta$-actin (cat no. sc-7210; 1:200; Santa Cruz Biotechnology, Inc.) primary antibodies at $4^{\circ} \mathrm{C}$ for $12 \mathrm{~h}$. A corresponding bovine anti-rabbit $\operatorname{IgG}$ horseradish peroxidase-conjugated secondary antibody (cat no. sc-2370; 1:1,000; Santa Cruz Biotechnology, Inc.) was subsequently applied at room temperature for $2 \mathrm{~h}$. Following chemiluminescence reactions with enhanced chemiluminescence detection reagents kits (GE Healthcare, Chicago, IL, USA), according to the manufacturer's protocol, the membranes were visualized by exposure to X-ray film in the dark. Densitometric analysis was performed using Scion Image software (Scion Corporation, Frederick, MD, USA).

Anti-miR design and transfection. miR-302b inhibitor (A) and miR Inhibit or Negative Control (NC) were purchased from AngRang Inc. (Xi'an, China). The sequence for miR-302b inhibitor was 5'-CTACTAAAACATGGAAGCACTTA-3'. Cells were seeded on to a 24-well plate at a concentration of $1 \times 10^{5}$ cells/well. RNA oligonucleotides transfection $(50 \mathrm{nM})$ was performed with Lipofectamine 2000 (Invitrogen; Thermo Fisher Scientific, Inc.) according to the manufacturer's protocol. Fresh growth medium (RPMI-1640) was changed $6 \mathrm{~h}$ after transfection, and the cells were harvested for analysis $48 \mathrm{~h}$ after transfection.

Statistical analysis. Data are expressed as the mean \pm standard error of the mean from $\geq 3$ separate experiments performed in 
A

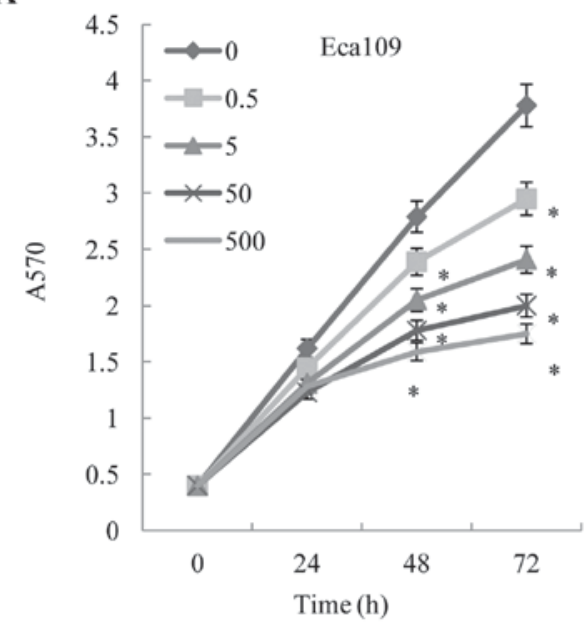

C

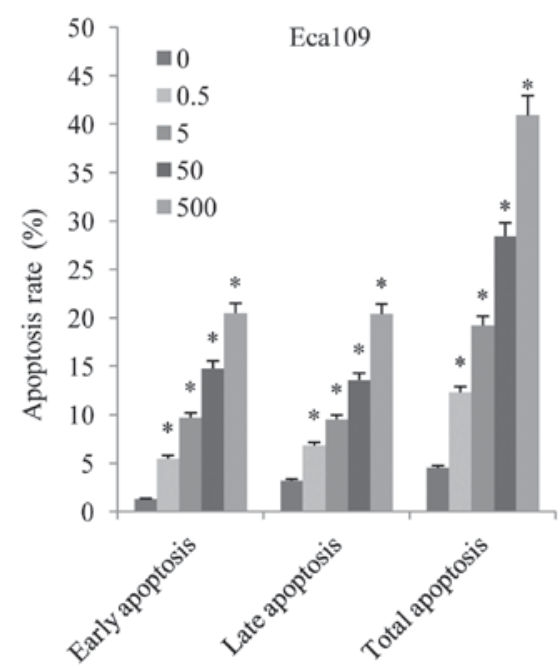

B

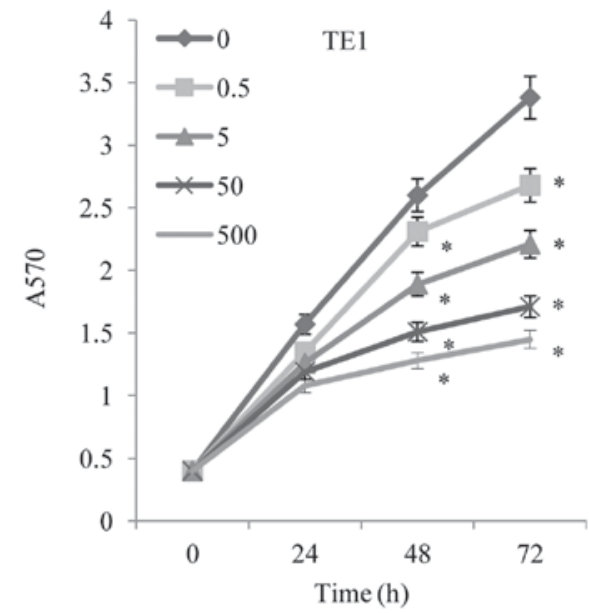

D

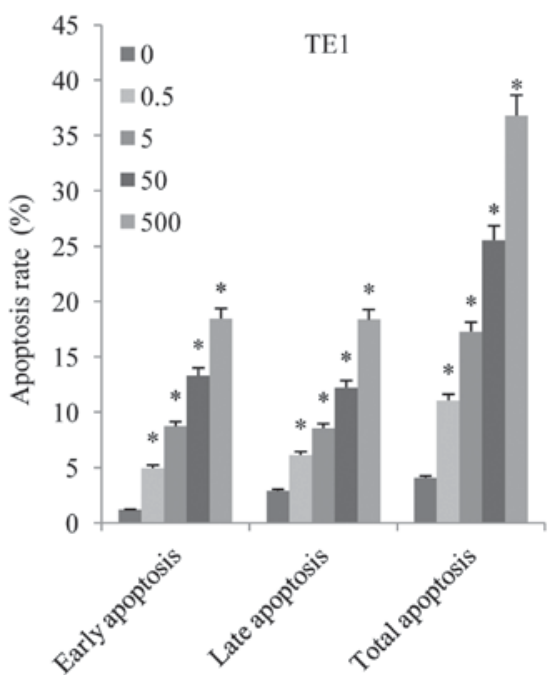

Figure 1. Effects of fentanyl stimulation on cell proliferation and apoptosis. Cells were incubated with increasing concentrations ( $0,0.5,5,50$ and 500 ng/ml) of fentanyl. Fentanyl inhibited the proliferation of (A) Eca109 or (B) TE1 cells in a time- and dose-dependent manner. Apoptosis analysis using flow cytometry demonstrated that fentanyl promoted the apoptosis of (C) Eca109 and (D) TE1 cells. All these results confirmed that fentanyl (at a concentration $\geq 5$ ng/ml) significantly inhibited proliferation and induced apoptosis in the two cell lines. Data are presented as the mean \pm standard deviation of three independent experiments. ${ }^{*} \mathrm{P}<0.05$ vs. the group with the previous (lower) dose of fentanyl. A, absorbance.

triplicate. Differences among groups were assessedby aone-way analysis of variance (followed by Student-Newman-Keuls) using SPSS 13.0 (SPSS, Inc., Chicago, IL, USA). P<0.05 was considered to indicate a statistically significant difference.

\section{Results}

Effect of fentanyl on cell proliferation, apoptosis and invasion. The present study initially investigated the effects of fentanyl on cell proliferation, apoptosis and invasion. The Eca109 and TE1 cell lines were cultured in the presence of various concentrations $(0.5,5,50$ and $500 \mathrm{ng} / \mathrm{ml})$ of fentanyl and the cell proliferation were measured using MTT assays. As demonstrated in Fig. 1A and B, the proliferation of the Eca109 and TE1 cells was inhibited by fentanyl in a dose- and time-dependent manner. Fentanyl significantly inhibited cell proliferation at 48 and $72 \mathrm{~h}$. In order to further quantify cell death, Annexin V/PI analysis was performed. Following exposure to fentanyl for 48 h, Eca109 cells exhibited a decreasing rate of apoptosis (Fig. 1C and D). The cell invasion assay also revealed that fentanyl significantly stimulated invasion in a concentration-dependent manner (Fig. 2A-C). Concentrations of fentanyl $>5 \mathrm{ng} / \mathrm{ml}$ exhibited a significant inhibitory effect on cell proliferation and metastasis. Therefore, a concentration of $5 \mathrm{ng} / \mathrm{ml}$ was selected for the subsequent experiments.

miR-302b is involved in the effect of fentanyl on ESCC behaviors. It was previously revealed that miR-302b suppressed proliferation by inducing apoptosis and repressed the invasion of ESCC cells through targeting ErbB4 (13). The present study further investigated whether or not miR-302b is also involved in the effect of fentanyl on the biological behaviors of ESCC. An miR-302b inhibitor (anti-miR-302b) was used to block miR-302b expression in ESCC cells, with the results demonstrating that fentanyl increased the expression of miR-302b, and that anti-miR-302b reversed the upregulation of miR-302b (Fig. 3A and B). Subsequently, the effects of altered miR-302b expression on the anti-proliferation, pro-apoptosis and anti-invasion effects induced by fentanyl 
A
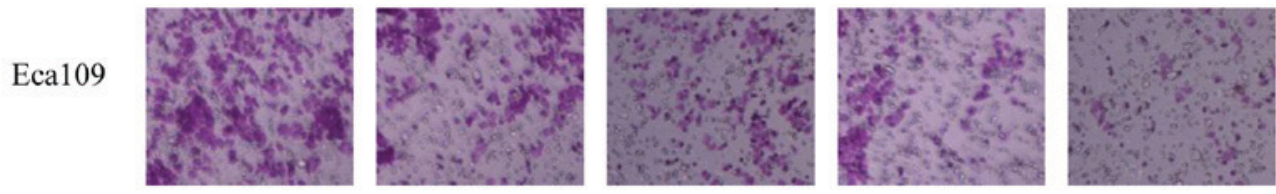

TE1

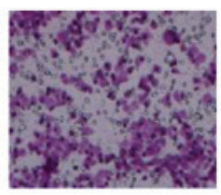

0

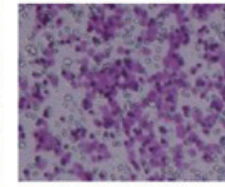

0.5

\section{B}

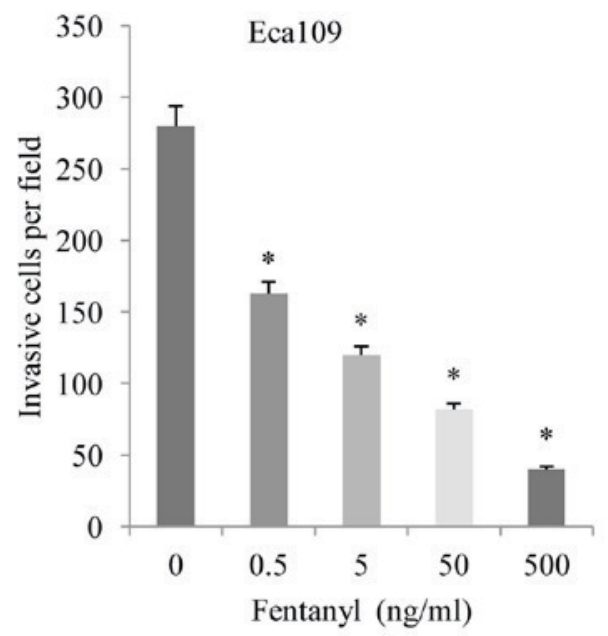

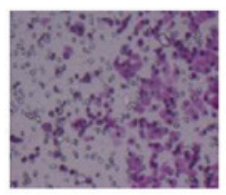

5

Fentanyl (ng/ml)

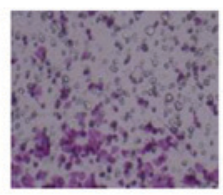

50

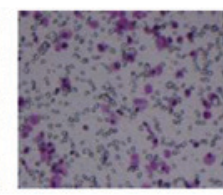

500

C

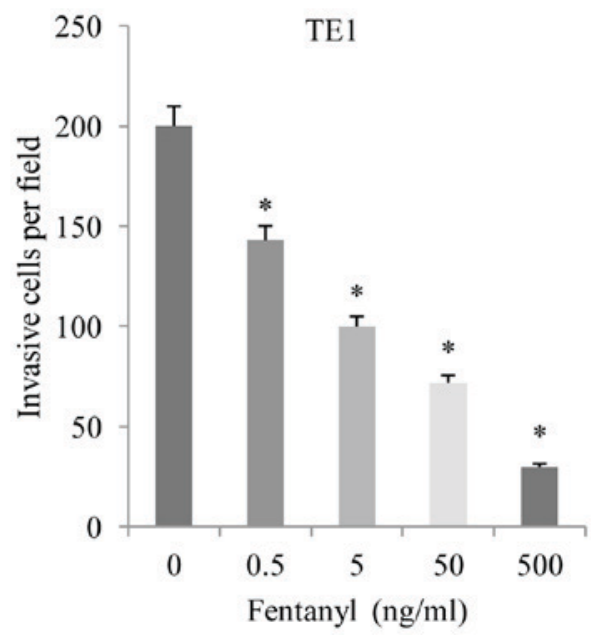

Figure 2. Effects of fentanyl stimulation on cell invasion. Cells were incubated with increasing concentrations $(0,0.5,5,50 \mathrm{and} 500 \mathrm{ng} / \mathrm{ml})$ of fentanyl. (A) Effect of fentanyl on cell invasion was detected using a Transwell assay. The cell invasion assay revealed that fentanyl significantly reversed the invasion of (B) Eca109 and (C) TE1 cells. All these results confirmed that fentanyl (at a concentration of $\geq 5 \mathrm{ng} / \mathrm{ml}$ ) significantly reversed invasion. Values are presented as the mean \pm standard deviation of three independent experiments. $\mathrm{P}<0.05$ vs. the group treated with the previous (lower) dose of fentanyl.

in ESCC were detected. It was revealed that downregulation of miR-302b reversed the anti-proliferation (Fig. 3C and D), pro-apoptosis (Fig. 3E and F) and anti-invasion (Fig. 4A-C) effects of fentanyl in the two ESSC cell lines.

Fentanyl upregulated the expression of miR-302b in ESSC cells. The present study analyzed the effects of fentanyl on the expression levels of miR-302b. As demonstrated in Fig. 5, following treatment with fentanyl for $48 \mathrm{~h}$, the expression level of miR-302b increased significantly in the two ESCC cells in a dose-(Fig. 5A and B) and time-(Fig. 5C and D) dependent manner, according to the RT-qPCR results.

Fentanyl downregulated the expression of ErbB 4, but this effect was reversed by anti-miR-302b transfection in ESSC cells. ERBB4 is one of the down-stream targets of miR-302b (14); therefore, we hypothesized that fentanyl modified the behaviors of ESCC cells through suppressing ErbB4. As demonstrated in Fig. 6, fentanyl decreased the expression of ErbB4 at the transcriptional (Fig. 6A) and translational levels (Fig. 6B) in a dose-dependent manner. However, the suppressive effect of fentanyl on ErbB4 expression was subsequently reversed by anti-miR-302b transfection (Fig. 6A and B), demonstrating the effects of miR-302b on the ability of fentanyl to inhibit the activation of ErbB4.

\section{Discussion}

Cancer is a major public health issue in the majority of countries, including China. Cancer is often treated by chemotherapy, immunotherapy, radiation and surgery. Anesthesia serves an important role in surgery, ensuring the safety and comfort of patients during procedures (16). However, numerous anesthetic agents are used without knowledge of their effects on cancer. Recently, it has been suggested that certain anesthetic drugs may modify malignant biological behaviors, including proliferation, angiogenesis and apoptosis in certain cancer cells (17). Nevertheless, the possible role of anesthetic drugs in cancer development and progression remains unclear.

Fentanyl is widely used in clinic as an anesthetic, particularly in the treatment of different types of cancer, including ESCC (18). Previous studies have reported the potential antitumor effects of fentanyl, but there are limited reports regarding its role in ESCC (6-10). The results of the present study suggested that the mechanisms of the anti-proliferation and anti-invasion effects of fentanyl were associated with 
A

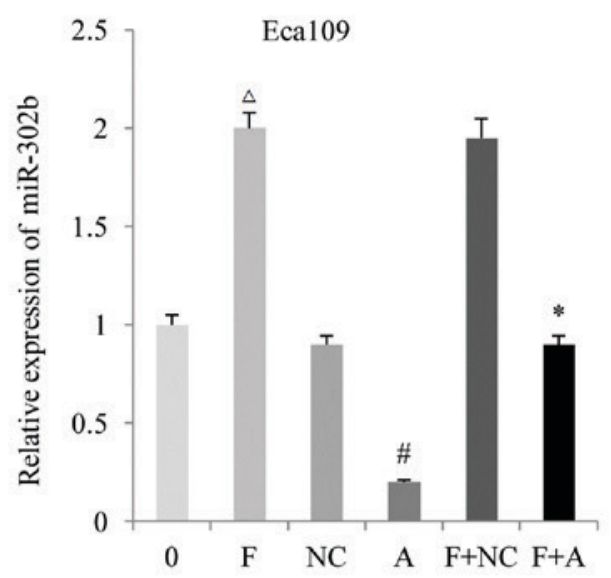

C

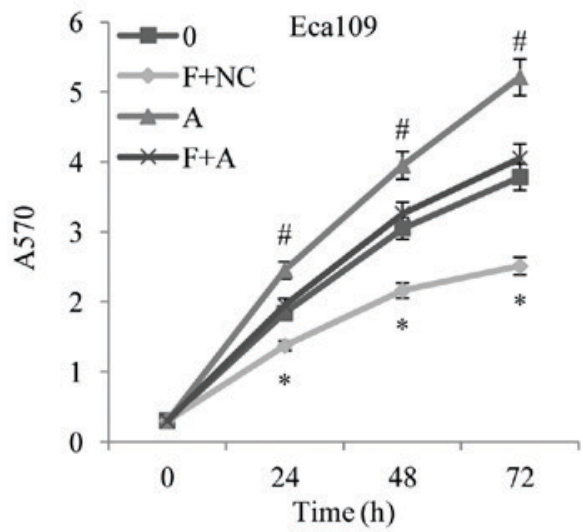

$\mathbf{E}$

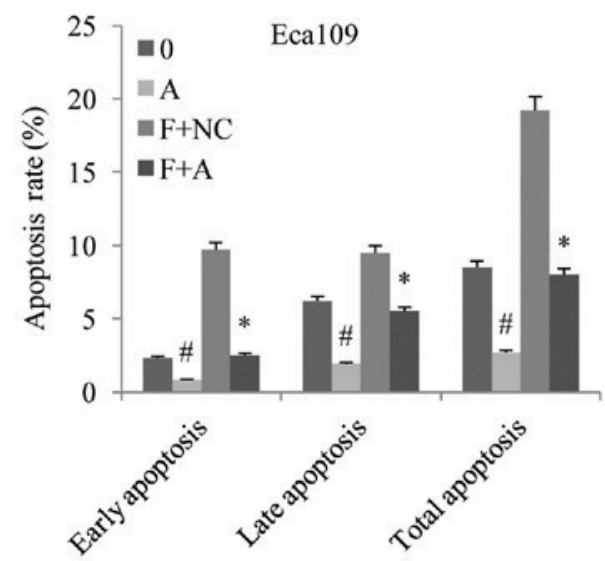

B

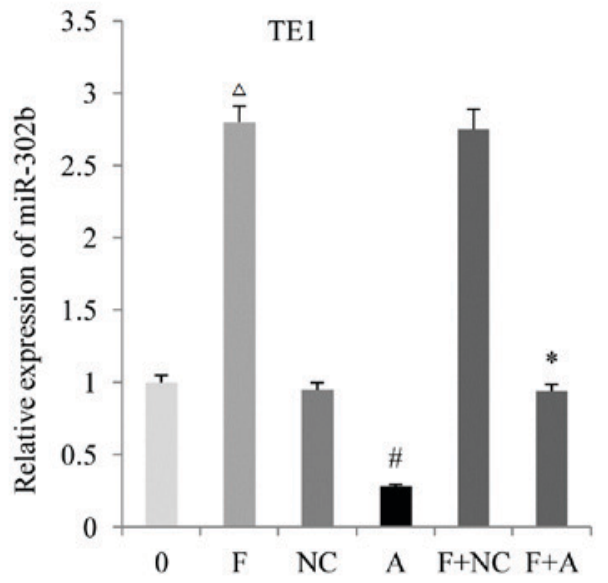

D
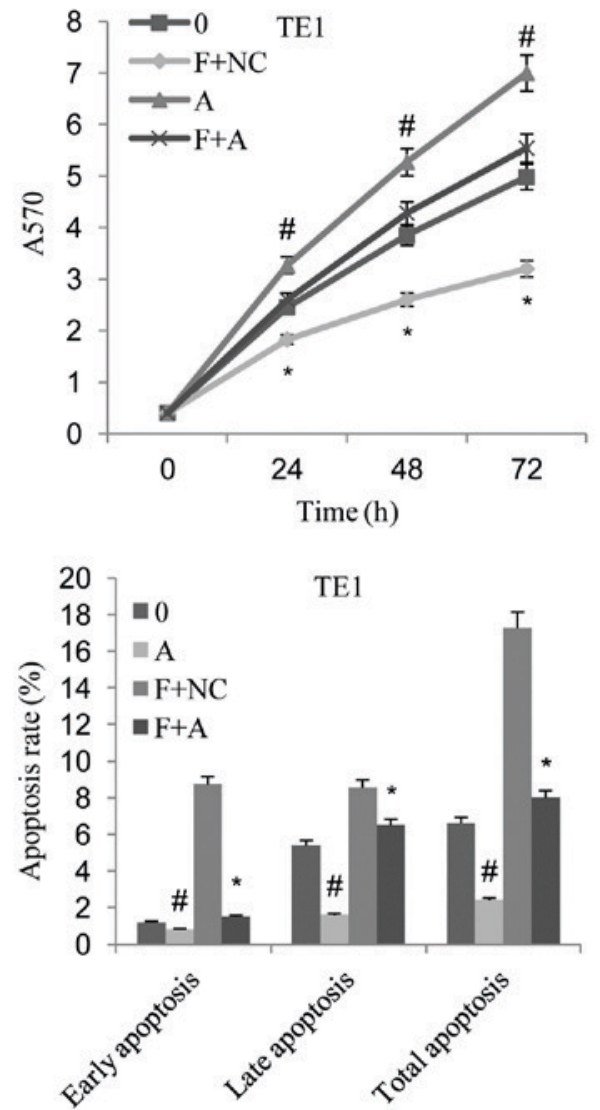

Figure 3. Effects of downregulation of miR-302b on the cell proliferation inhibition induced by fentanyl. Expression of miR-302b in (A) Eca109 or (B) TE1 cells treated withanti-miR-302b and/or fentanyl $(5 \mathrm{ng} / \mathrm{ml}$; detected by quantitative polymerase chain reaction. MTT was used to assess the effects of downregulation of miR-302b on the proliferation (induced by $5 \mathrm{ng} / \mathrm{ml}$ fentanyl) of (C) Eca109 and (D) TE1 cells, and flow cytometry was used to assess the effects of downregulation of miR-302b on the apoptosis (induced by $5 \mathrm{ng} / \mathrm{ml}$ fentanyl) of (E) Eca109 and (F) TE1 cells. Downregulation of miR-302b reversed the anti-proliferation and pro-apoptosis effects induced by fentanyl in Eca109 and TE1 cells. Data are presented as the mean \pm standard deviation of three independent experiments. ${ }^{\mathrm{P}} \mathrm{P}<0.05$ vs. $0 ;{ }^{*} \mathrm{P}<0.05$ vs. 0 or NC; ${ }^{*} \mathrm{P}<0.05$ vs. F+NC. miR, microRNA; 0 , cells without fentanyl exposure; F, cells treated with fentanyl $(5 \mathrm{ng} / \mathrm{ml}) ; \mathrm{NC}$, negative control of anti-miR-302b; A, cells treated with anti-miR-302b.

miR-302b expression in ESCC Eca109 and TE1 cell lines. Accompanied by the malignant biological behaviors changes, the expression of miR-302b was elevated by fentanyl treatment. Furthermore, ErbB4 was targeted and inhibited by increased miR-302b expression. Notably, the application of anti-miR-302b impaired the anti-proliferation and anti-invasion effects of fentanyl. These results supported our hypothesis that fentanyl inhibited the proliferation and invasion of ESCC cells by stimulating the expression of miR-302b which, in turn, downregulated the expression of ErbB4.

miR-302b is a member of the miR-302 cluster, which regulates the regulatory circuitry controlling ES cell 'stemness' (19). Previously, it was revealed that miR-302b acted as a tumor suppressor by post-transcriptionally regulating different types of oncogenes. miR-302b was able to inhibit proliferation $(20,21)$, induce apoptosis $(22,23)$ and 
A

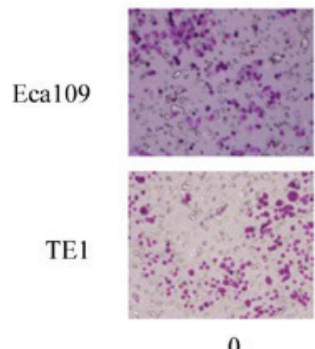

0

B

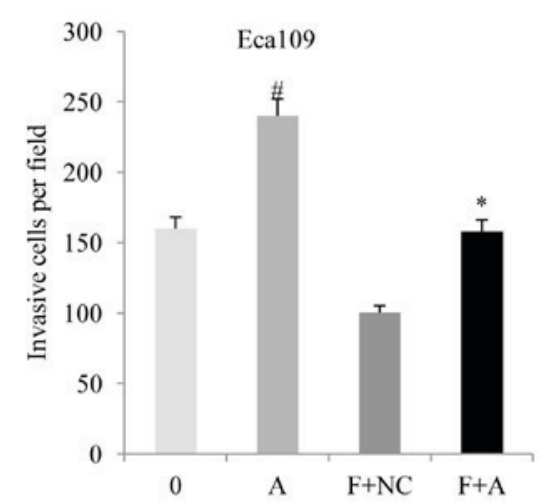

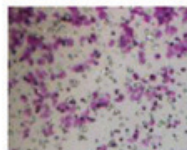

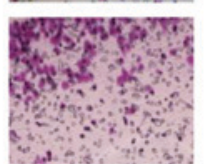

C
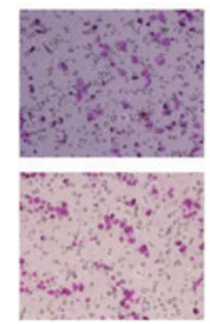

$\mathrm{F}+\mathrm{NC}$
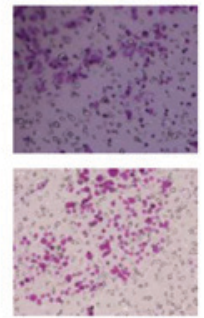

$\mathrm{F}+\mathrm{A}$

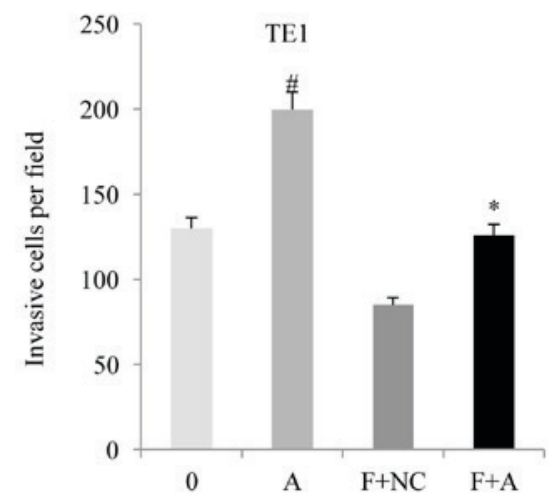

Figure 4. Effects of downregulation of miR-302b on the cell invasion inhibited by fentanyl. (A) Transwell assays were used to assess the effects of downregulation of miR-302b on the invasion inhibited by fentanyl $(5 \mathrm{ng} / \mathrm{ml})$. Downregulation of miR-302b reversed the anti-invasion induced by fentanyl in (B) Eca109 and (C) TE1 cells. Data are represented as the mean \pm standard deviation of three independent experiments. ${ }^{\#} \mathrm{P}<0.05$ vs. $0 ;{ }^{*} \mathrm{P}<0.05$ vs. F+NC. miR, microRNA; 0, cells without fentanyl exposure; F, cells treated with fentanyl (5 ng/ml); NC, negative control of anti-miR-302b; A, cells treated with anti-miR-302b.

A

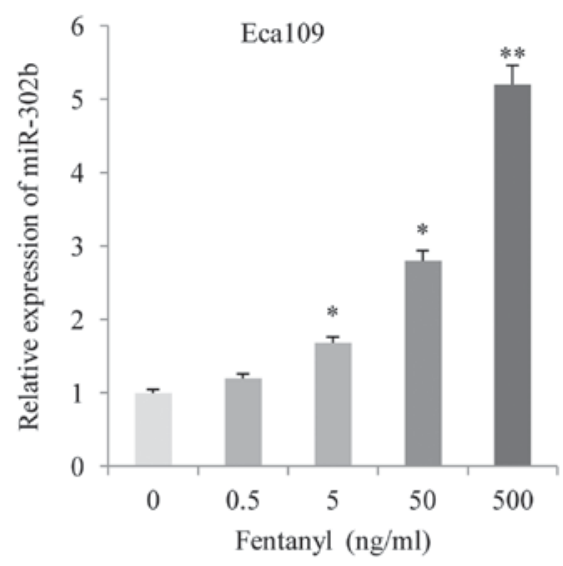

C

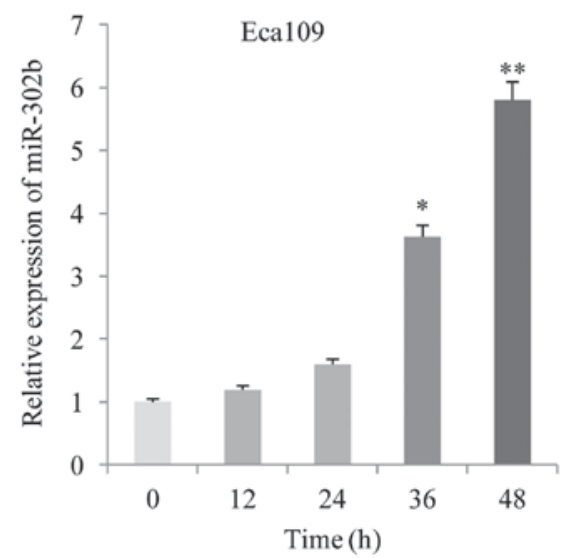

B

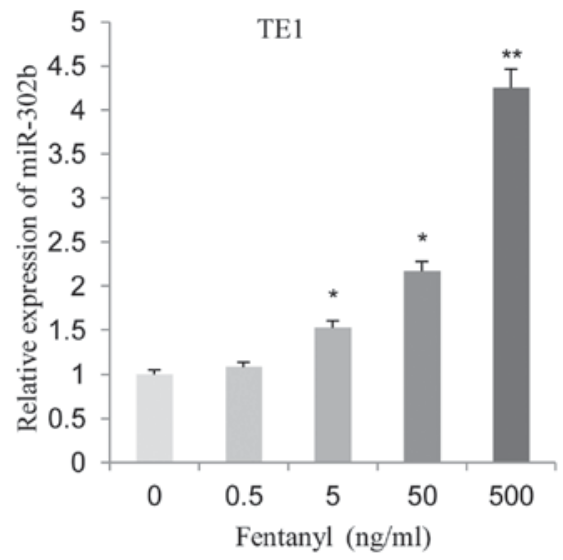

D

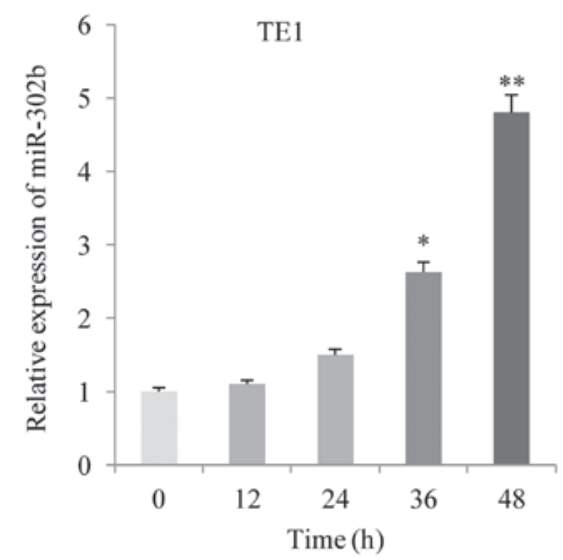

Figure 5. Effects of fentanyl on the expression of miR-302b in Eca109 and TE1 cells. (A) Eca109 and (B) TE1 cells were treated with different concentrations $(0,0.5,5,50$ and $500 \mathrm{ng} / \mathrm{ml})$ of fentanyl for $48 \mathrm{~h}$. (C) Eca109 and (D) cells were treated with fentanyl $(5 \mathrm{ng} / \mathrm{ml})$ for different times $(0,12,24,36$ and $48 \mathrm{~h})$. Quantitative polymerase chain reaction was used to evaluate the expression of miR-302b. Fentanyl upregulated the expression of miR-302b in the two cell lines in a dose- and time-dependent manner. Representative results are from three independent experiments are demonstrated. ${ }^{*} \mathrm{P}<0.05$ or ${ }^{* * *} \mathrm{P}<0.01$ vs. the group treated with previous (lower) dose of fentanyl. 
A

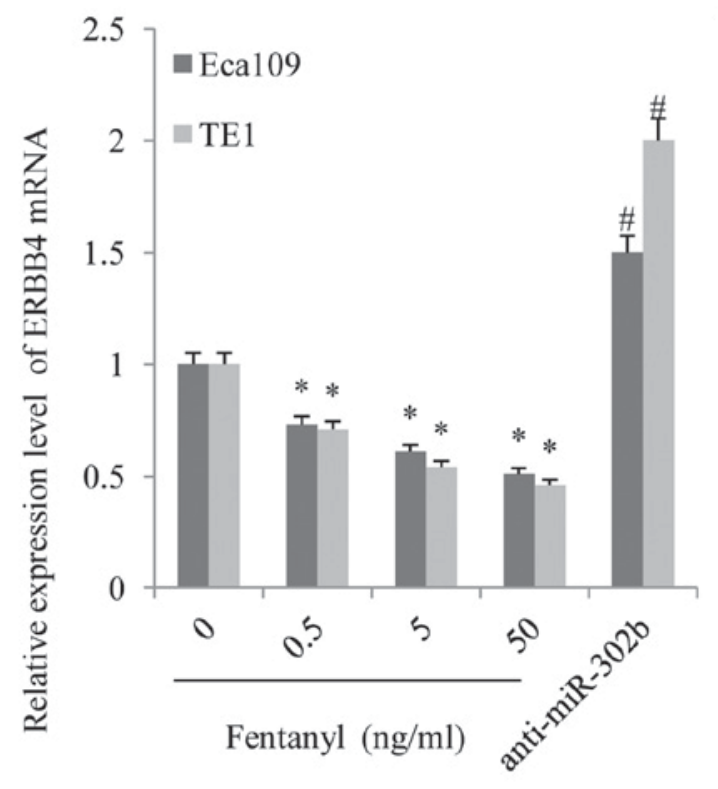

B

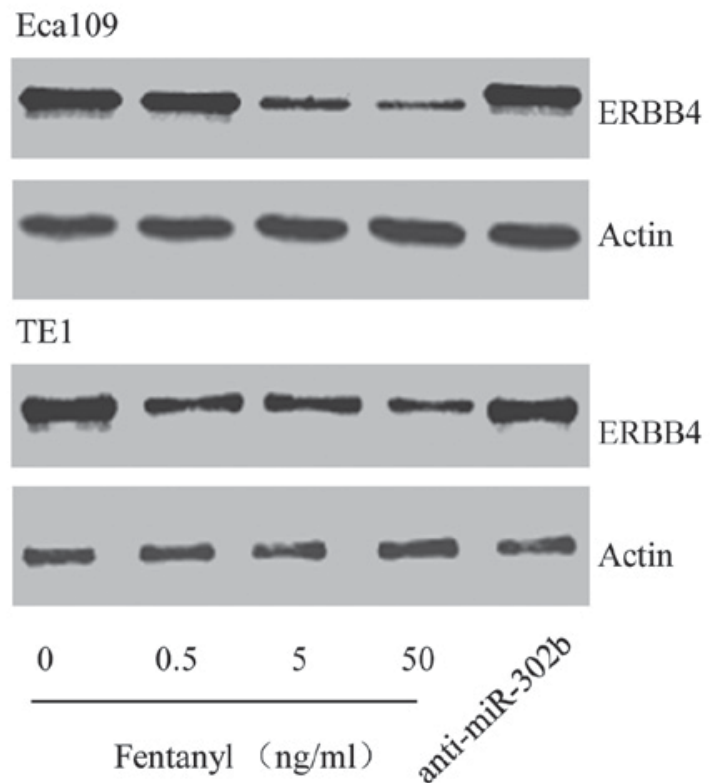

Figure 6. Effects of fentanyl and anti-miR-302b on the activation of ERBB4 in Eca109 and TE1 cells. The relative (A) mRNA and (B) protein expression of ERBB4 was detected by reverse transcription-quantitative polymerase chain reaction or western blot, respectively, in Eca109 and TE1 treated with increasing concentrations $(0,0.5,5$ and $50 \mathrm{ng} / \mathrm{ml})$ of fentanyl or anti-miR-302b. The results demonstrated that fentanyl decreased ERBB4 expression while anti-miR-302b increased it. Each experiment was performed three times in triplicate. ${ }^{*} \mathrm{P}<0.05$ vs. the group treated with the previous (lower) dose of fentanyl, ${ }^{\#} \mathrm{P}<0.05$ vs. control (cells without fentanyl exposure).

enhance chemotherapy sensitivity $(24,25)$. A previous study revealed that miR-302b was a potential molecular marker of ESCC and that it acts as a tumor suppressor by targeting ErbB4 (13).

ErbB4, one of the potential targets in ESCC, is one of members of the ErbB/HER subfamily, which regulates cellular proliferation, differentiation and programmed cell death (26). Xu et al (27) revealed that extra-nuclear ErbB4 had negative effects on the progression of ESCC, while the nuclear translocation of ErbB4 exhibited a tumor-promoting property. Zhao et al (28) reported that ErbB4 served as a potential molecular target in the treatment of ESCC. Therefore, activation of ErbB4 may promote proliferation and invasion in ESCC. The results of the present study demonstrated that, accompanied by elevation of miR-302b in ESCC cells, fentanyl treatment also downregulated the expression of ErbB4, thereby inhibiting proliferation and invasion. Furthermore, fentanyl failed to downregulate the expression of ErbB4 in cells transfected with anti-miR-302b, which also impaired the inhibitory effects of fentanyl against the proliferation and invasion of these cells through miR-302b.

In summary, to the best of our knowledge, the present study is the first to identify the involvement of miR-302b in the anti-proliferation and anti-invasion effects of fentanyl in ESCC. Based on the results in the present study, it was concluded that fentanyl inhibited the proliferation and invasion of ESCC cells by elevating the expression of miR-302b and, in turn, suppressing the activation of ErbB4. However, the manner in which fentanyl treatment regulatesmiR-302b expression in ESCC cells remains unknown and requires further study.

\section{Acknowledgements}

Not applicable.

\section{Funding}

No funding was received.

\section{Availability of data and materials}

The datasets used and/or analyzed during the current study are available from the corresponding author on reasonable request.

\section{Authors' contributions}

NW and ZZ conceived the study. NW and JL wrote and edited the main manuscript. JL and $\mathrm{ZZ}$ designed the experiments. $\mathrm{NW}, \mathrm{ZZ}$ and JL performed the experiments and analyzed the data.

\section{Ethics approval and consent to participate}

Not applicable.

\section{Consent for publication}

Not applicable.

\section{Competing interests}

The authors declare that they have no competing interests. 


\section{References}

1. Jemal A, Bray F, Center MM, Ferlay J, Ward E and Forman D: Global cancer statistics. CA Cancer J Clin 61: 69-90, 2011.

2. Siegel RL, Miller KD and Jemal A: Cancer statistics, 2015. CA Cancer J Clin 65: 5-29, 2015.

3. Chen W, Zheng R, Baade PD, Zhang S, Zeng H, Bray F, Jemal A, Yu XQ and He J: Cancer statistics in China, 2015. CA Cancer J Clin 66: 115-132, 2016.

4. Nuckols TK, Anderson L, Popescu I, Diamant AL, Doyle B, Di Capua P and Chou R: Opioid prescribing: A systematic review and critical appraisal of guidelines for chronic pain. Ann Intern Med 160: 38-47, 2014.

5. Mercadante S: Fentanyl buccal tablet for the treatment of cancer-related breakthrough pain. Expert Rev Clin Pharmacol 8: 9-13, 2015

6. Qin Y, Li L, Chen J, Tang X, Liao C, Xie Y and Xiao Q: Fentanyl inhibits progression of human gastric cancer MGC-803 cells by NF-kappaB downregulation and PTEN upregulation in vitro. Oncol Res 20: 61-69, 2012.

7. Nomura Y, Kawaraguchi Y, Sugimoto H, Furuya $H$ and Kawaguchi M: Effects of morphine and fentanyl on 5-fluorouracil sensitivity in human colon cancer HCT116 cells. J Anesth 28 298-301, 2014

8. Zhang XL, Chen ML and Zhou SL: Fentanyl inhibits proliferation and invasion of colorectal cancer via $\beta$-catenin. Int J Clin Exp Pathol 8: 227-235, 2015

9. Li AX, Xin WQ and Ma CG: Fentanyl inhibits the invasion and migration of colorectal cancer cells via inhibiting the negative regulation of Ets-1 on BANCR. Biochem Biophys Res Commun 465: 594-600, 2015.

10. Miao J, Wang L, Chen L, Yang T, Jin L and Lin L: Fentanyl inhibits cell viability in human pancreatic cancer cell line and tumor growth in pancreatic cancer cell-transplanted mice. Int J Clin Exp Med 8: 17684-17693, 2015.

11. Ohtsuka M, Ling H, Doki Y, Mori M and Calin GA: MicroRNA processing and human cancer. J Clin Med 4: 1651-1667, 2015.

12. Zhang M, Zhou S, Zhang L, Zhang J, Cai H, Zhu J, Huang C and Wang J: miR-518b is down-regulated, and involved in cell proliferation and invasion by targeting Raplb in esophageal squamous cell carcinoma. FEBS Lett 586: 3508-3521, 2012.

13. Zhang M, Yang Q, Zhang L, Zhou S, Ye W, Yao Q, Li Z, Huang C, Wen Q and Wang J: miR-302b is a potential molecular marker of esophageal squamous cell carcinoma and functions as a tumor suppressor by targeting ErbB4. J Exp Clin Cancer Res 33: 10 2014.

14. Zhou S, Ye W, Ren J, Shao Q, Qi Y, Liang J and Zhang M: MicroRNA-381 increases radiosensitivity in esophageal squamous cell carcinoma. Am J Cancer Res 5: 267-277, 2014.
15. Livak KJ and Schmittgen TD: Analysis of relative gene expression data using real-time quantitative PCR and the 2(-Delta Delta C(T)) method. Methods 25: 402-408, 2001.

16. Ciechanowicz SJ and Ma D. Anaesthesia for oncological surgery-can it really influence cancer recurrence? Anaesthesia 71: 127-131, 2016.

17. Santamaria LB, Schifilliti D, La Torre D and Fodale V: Drugs of anaesthesia and cancer. Surg Oncol 19: 63-81, 2010.

18. Tai YH, Wu HL, Chang WK, Tsou MY, Chen HH and Chang KY: Intraoperative fentanyl consumption does not impact cancer recurrence or overall survival after curative colorectal cancer resection. Sci Rep 7: 10816, 2017.

19. Lin SL, Chang DC, Chang-Lin S, Lin CH, Wu DT, Chen DT and Ying SY: Mir-302 reprograms human skin cancer cells into a pluripotent ES-cell-like state. RNA 14: 2115-2124, 2008.

20. Wang L, Yao J, Shi X, Hu L, Li Z, Song T and Huang C: MicroRNA-302b suppresses cell proliferation by targeting EGFR in human hepatocellular carcinoma SMMC-7721 cells. BMC Cancer 13: 448, 2013

21. Wang L, Yao J, Zhang X, Guo B, Le X, Cubberly M, Li Z, Nan K, Song $\mathrm{T}$ and Huang C: miRNA-302b suppresses human hepatocellular carcinoma by targeting AKT2. Mol Cancer Res 12: 190-202, 2014

22. Zhang $\mathrm{Y}, \mathrm{Hu} \mathrm{H}$, Song $\mathrm{L}$, Cai L, Wei $\mathrm{R}$ and Jin W: Epirubicin-mediated expression of miR-302b is involved in osteosarcoma apoptosis and cell cycle regulation. Toxicol Lett 222: 1-9, 2013.

23. Chen $\mathrm{PH}$, Shih $\mathrm{CM}$, Chang WC, Cheng $\mathrm{CH}$, Lin $\mathrm{CW}$, Ho KH, Su PC and Chen KC: MicroRNA-302b-inhibited E2F3 transcription factor is related to all trans retinoic acid-induced glioma cell apoptosis. J Neurochem 131: 731-742, 2014.

24. Cai D, He K, Chang S, Tong D and Huang C: MicroRNA-302b Enhances the Sensitivity of Hepatocellular Carcinoma Cell Lines to 5-FU via Targeting Mcl-1 and DPYD. Int J Mol Sci 16: 23668-23682, 2015.

25. Cataldo A, Cheung DG, Balsari A, Tagliabue E, Coppola V, Iorio MV, Palmieri D and Croce CM: miR-302b enhances breast cancer cell sensitivity to cisplatin by regulating E2F1 and the cellular DNA damage response. Oncotarget 7: 786-797, 2016.

26. Zhang L, Ma J, Han Y, Liu J, Zhou W, Hong L and Fan D: Targeted therapy in esophageal cancer. Expert Rev Gastroenterol Hepatol 10: 595-604, 2016.

27. Xu S, Kitayama J, Yamashita H, Souma D and Nagawa $\mathrm{H}$. Nuclear translocation of HER-4/c-erbB-4 is significantly correlated with prognosis of esophageal squamous cell carcinoma. J Surg Oncol 97: 44-50, 2008.

28. Zhao K, Chen BJ and Chen ZG: ErbB4 as a potential molecular target in the treatment of esophageal squamous cell cancers. ScientificWorldJournal 2014: 124105, 2014. 